\title{
Efficacy of Anbioflam Syrup in Wounds and Dermatological Disorders in Dogs
}

\author{
G. U. Yadav*, D. U. Lokhande and R. S. Gandge \\ Mumbai Veterinary College, Parel, Mumbai -400012, India \\ *Corresponding author
}

\begin{tabular}{|l|}
\hline Ke y w o r d s \\
Anbioflam syrup, \\
$\begin{array}{l}\text { Wounds and } \\
\text { dermatological } \\
\text { disorders }\end{array}$ \\
\hline Article Info \\
\hline $\begin{array}{l}\text { Accepted: } \\
18 \text { May } 2020 \\
\text { Available Online: } \\
\text { 10 June } 2020\end{array}$ \\
\hline
\end{tabular}

\section{A B S T R A C T}

Twenty clinical surgical cases various wounds, dermatitis, other acute or chronic inflammatory conditions of dogs, the dogs operated for surgeries like ear hematoma, castration, spaying, amputation of limb, bone plating, bone pinning, pyometra, resuturing of wounds were selected for the present study. Efficacy of Anbioflam Syrup in acute and chronic inflammation, wounds was studied. All the cases were treated with AnblioFlam Systemic $10 \mathrm{ml}$ daily for 15 days Clinical signs of different clinical surgical cases viz.Redness, abnormal heat, swelling, pain vascular and exudative change, abscess subsided 7-15 days after treatment with Anbioflam Syrup.Complete blood count revealed no significant changes before and after treatment, The bacteriological investigation of these samples revealed that five samples after treatment turned to be negative for bacterial infection.

\section{Introduction}

The AnbioFlam is an ayurvedic antinflammatory preparation can be used safely in various wounds, dermatitis, other acute or chronic inflammatory conditions.And other dermatological conditions without any side effects. It can be used fungal and bacterial skin infections such as Ringworm, Eczema, Pyoderma etc. It can also be used for systemic support for faster healing of different kinds of wounds, difficult and chronic skin affections, generalized skin lesions and alopecia.
Anbioflam syrup contains the Cedrus deodara wood oil which has significant inhibitory activity against exudative proliferative and chronic phases of inflammation. Also Anbioflam syrup contains Curcuma longa Rhizome oil which is antioxidant, antiinflammatory, antifungal, antibacterial activities (Shinde et al., 1999 and Negi et al., 1999).

[Anbioflam Syrup-Indian Herbs Specialities Pvt. Ltd. Saharanpur.] 


\section{Materials and Methods}

Twenty clinical surgical cases various wounds, dermatitis, other acute or chronic inflammatory conditions of dogs, the dogs operated for surgeries like ear hematoma, castration, spaying, amputation of limb, bone plating, bone pinning, pyometra, resuturing of wounds etc.presented to Department of Surgery and Radiology, TVCC and The Bai Sakarbai Dinshaw Petit Hospital affiliated to Mumbai Veterinary College Parel, Mumbai were selected for the present study. Efficacy of Anbioflam Syrup in acute and chronic inflammation, wounds was studied. All the cases were treated with AnblioFlam Systemic $10 \mathrm{ml}$ daily for 15 days. Clinical signs of different clinical surgical cases viz.Redness, abnormal heat, swelling, pain vascular and exudative change, abscess were subsided 7 to 15 days after treatment. Recovery on the basis of clinical signs and hematological \&biochemical parameters, skin culture \&sensitivity and laboratory tests like CBC, culture and sensitivity, total Viable Count before and 15 days after treatment andrecovery were assessed.

\section{Results and Discussion}

Anbioflam syrup can be used for dermatitis and other acute or chronic inflammatory conditions, fungal and bacterial skin infections such as ringworm, eczema, pyoderma etc. It can also be used as systemic support for faster healing of different kinds of wounds, difficult and chronic skin affections, generalized skin lesions and alopecia. The wood of $C$. deodara has been used since ancient days in Ayurvedic medical practice for the treatment of inflammations and rheumatoid arthritis Kirtikar and Basu, (1933). In the present study twenty clinical surgical cases of dogs suffering from having acute, chronic inflammation and wounds Dogs operated for surgeries like ear hematoma, castration, spaying, amputation of limb, bone plating, bone pinning, pyometra, resuturing of wounds etc. In all the dogs Syp. Anbioflam $10 \mathrm{ml}$ once daily was given for 15 days.

The details of results obtained are as follows.

\section{Redness}

Redness at the site of inflammation was present in all 20 (100\%) cases before treatment with Anbioflam and it was reduced in $17(85 \%)$ cases 7 days after treatment with Anbioflam and was absent in 19 (95\%) cases 15 days after treatment with Anbioflam. It indicates that Syp. Anbioflam is very useful to reduce the sign of redness in inflammatory conditions. The Curcuma longa and. $C$. deodara present in the Anbioflam syrup acts as anti- inflammatory analgesic and redness in the tissue is reduced Vijayastelter (2011). $C$. Deodara present in the Anbioflam syrup inhibited neutrophil adhesion to nylon fibers, indicating inhibition of process of margination in the blood vessels Shinde et al., (1999).

\section{Abnormal heat}

Abnormal heat was observed in 15 (75\%) cases before treatment with Anbioflam. It was reduced in $7(46.66 \%)$ cases and was slightly present in $8(54.44 \%)$ cases 7 days after treatment with Anbioflam whereas it was totally absent in all 15 (75\%) of the cases after 15 days of treatment with Anbioflam. It shows that syrup Anbioflam is effective in reducing abnormal heat which is one of sign of inflammation at the site of inflamed tissues. This may be due to the antiinflammatory and analgesic effect of Anbioflam syrup which contains Curcuma longa and C. deodara (Vijayastelter, 2011 and Shinde et al., 1999). 


\section{Exudative changes}

Exudative changes were present in all 20 $(100 \%)$ cases before treatment with Anbioflam. They were reduced in 16 (80\%) 7 days after treatment with Anbioflam and were absent in all $20(100 \%)$ cases 15 days after treatment with Anbioflam. It denotes that syrup Anbioflam is very effective to reduce exudative changes. This may be due to the mast cell stabilizing activity of $C$. deodara wood oil (Shinde et al., 1999). Curcuma longa prevents release of histamine, 5hydroxytryptamine, prostaglandins, and bradykinin which subsides the edema in the tissue (Vijayastelter, 2011).

\section{Swelling}

Swelling was due to inflammation was present in all $20(100 \%)$ cases of dogs before treatment with Anbioflam. It was reduced in 17(85\%) cases 7 days after treatment with Anbioflam and was absent in 19 (95\%) cases 15 days after treatment with Anbioflam. It shows that syrup Anbioflam is very effective in reduction of inflammatory swelling is dogs.

This indicates that at the site of inflammation $C$. deodara wood oil reduces the number of neutrophils, thus decreasing their phagocytosis action and the release of various enzymes and mediators that make inflammation worse Shinde et al., 1999). Curcuma longa inhibits liberation of histamine and serotonin from mast cells in inflammatory reaction and prevents the edema in the tissues (Vijayastelter, 2011).

\section{Pain}

Pain was present in all the cases before treatment with Anbioflam. It was reduced in 19 (95\%) cases 7 days after treatment with Anbioflam and was completely reduced in all $20(100 \%)$ cases after 15 days of treatment. It is suggestive of effectiveness of syrup Anbioflam in reducing the pain. This might be due to the anti-inflammatory and analgesic activity Cedrus deodara and Curcuma longa resent in the Anbioflam syrup Shinde et al., (1999) and Vijayastelter (2011).

\section{Vascular changes}

Vascular changes were present in $20(100 \%)$ cases before treatment with Anbioflam. They were reduced in 19 (95\%) cases 7 days after treatment with Anbioflam and were completely absent in all $20(100 \%)$ cases 15 days after treatment with Anbioflam. It indicates that syrup Anbioflam is very effective in reducing the vascular changes. Cedrus deodarais anti-inflammatory, analgesic and anti-allergic and is effective in controlling exudative-proliferative and chronic phases of inflammation Shinde et al., (1999).

\section{Complete blood count}

CBC was performed in all the cases before and after treatment of Anbioflam treatment group which indicated there were no significant changes in the complete blood count 20 days after treatment with Anbioflam.

\section{Bacterial culture and antibiotic sensitivity test}

The aerobic bacterial culture for isolation non fastidious bacteria was carried out using suitable media. Identification of the recovered isolates was done based on morphology, colony characters and biochemical tests. The antibiotic sensitivity test of recovered isolates was carried out on Muller and Hinton Agar using nine (09) selected antibiotics by disc diffusion method.

A total 40 swab samples ( 20 before +20 after treatment) were studied. The bacteriological 
investigation of these samples revealed that five samples after treatment turned to be negative for bacterial infection. Out of total 36 bacterial isolates recovered, 13 were identified as Staphylococcus species, as Staphylococcus aureus, E.coli, Klebsiella spp, one Proteus spp. and showed Mixed infection.

Table.1 The details of Cases included in the present study are as follows

\begin{tabular}{|c|c|c|c|c|c|}
\hline $\begin{array}{l}\text { Case } \\
\text { No. }\end{array}$ & Breed & $\begin{array}{l}\text { Body } \\
\text { Weight }\end{array}$ & Age & Sex & Disease \\
\hline 1 & ND & $15 \mathrm{Kgs}$ & Adult & female & Large extensive wound on left medial thigh \\
\hline 2 & ND & $18 \mathrm{Kgs}$ & adult & female & Wound at the base of right ear \\
\hline 3 & ND & $16 \mathrm{kgs}$ & adult & male & $\begin{array}{l}\text { Wound on scrotum, purulent discharge, } \\
\text { necrotic skin of scrotum }\end{array}$ \\
\hline 4 & ND & $17.5 \mathrm{Kgs}$ & Adult & Female & $\begin{array}{l}\text { Large and deep incised wound on the left } \\
\text { thoracic area }\end{array}$ \\
\hline 5 & ND & $22 \mathrm{Kgs}$ & Adult & Female & Dehiscence of surgical site of mastectomy \\
\hline 6 & ND & $20 \mathrm{Kgs}$ & Adult & Male & $\begin{array}{l}\text { Extensive injury to the left hind limb with } \\
\text { bone exposed }\end{array}$ \\
\hline 7 & ND & $6 \mathrm{Kgs}$ & $\begin{array}{l}3 \\
\text { months }\end{array}$ & Male & $\begin{array}{l}\text { Injury to the left forepaw, bone exposure, } \\
\text { extreme purulence and edema }\end{array}$ \\
\hline 8 & ND & $18 \mathrm{Kgs}$ & 3 Years & Male & $\begin{array}{l}\text { Limb amputation left hind limb, post op } \\
\text { hematoma, bleeding and extensive erythema } \\
\text { and bruising }\end{array}$ \\
\hline 9 & ND & $16 \mathrm{Kgs}$ & $\begin{array}{l}7 \\
\text { months }\end{array}$ & Male & $\begin{array}{l}\text { Extensive injury on right forepaw, exposure of } \\
\text { the necrotic metacarpal }\end{array}$ \\
\hline 10 & ND & $10 \mathrm{Kgs}$ & 8 years & Male & $\begin{array}{l}\text { Recent injury \& deep wound on the muscles of } \\
\text { left metatarsals on the medial side. }\end{array}$ \\
\hline 11 & ND & $15 \mathrm{Kgs}$ & Adult & Male & Maggoted wound at the base of the tail \\
\hline 12 & ND & $12 \mathrm{Kgs}$ & 9 years & Male & Two extensive wounds on back \\
\hline 13 & ND & $12 \mathrm{Kgs}$ & 15 years & male & $\begin{array}{l}\text { Extensive wound separating dorsal \& ventral } \\
\text { surfaces of right ear, purulent, foul smelling } \\
\text { discharge }\end{array}$ \\
\hline 14 & ND & $15 \mathrm{Kgs}$ & 12 years & female & Two wounds on the rump with deep pockets \\
\hline 15 & ND & $12 \mathrm{Kgs}$ & adult & male & $\begin{array}{l}\text { Purulent wound above left eye extending up to } \\
\text { the base of the left ear }\end{array}$ \\
\hline 16 & ND & $14 \mathrm{Kgs}$ & adult & male & $\begin{array}{l}\text { Extensive wound on right ear involving its } \\
\text { dorsal surface and posterior border }\end{array}$ \\
\hline 17 & ND & $8 \mathrm{Kgs}$ & 6 years & male & $\begin{array}{l}\text { Maggot wound on left forelimb extending } \\
\text { from dorsal surface to ventral surface of } \\
\text { middle two digits }\end{array}$ \\
\hline 18 & ND & $6 \mathrm{Kgs}$ & $\begin{array}{l}7 \\
\text { months }\end{array}$ & female & $\begin{array}{l}\text { Post-surgical opening of sutures (hind leg } \\
\text { amputation) laceration \& purulent discharge }\end{array}$ \\
\hline 19 & Labrador & $25 \mathrm{Kgs}$ & 8 years & male & Deep maggoted wound below the anus \\
\hline 20 & ND & $14 \mathrm{Kgs}$ & 10 years & male & $\begin{array}{l}\text { Exudative wound with necrotic borders on the } \\
\text { left ear involving base of the ear }\end{array}$ \\
\hline
\end{tabular}


Case no.10 Dog having eczematous wound before treatment with Anbioflam Syrup

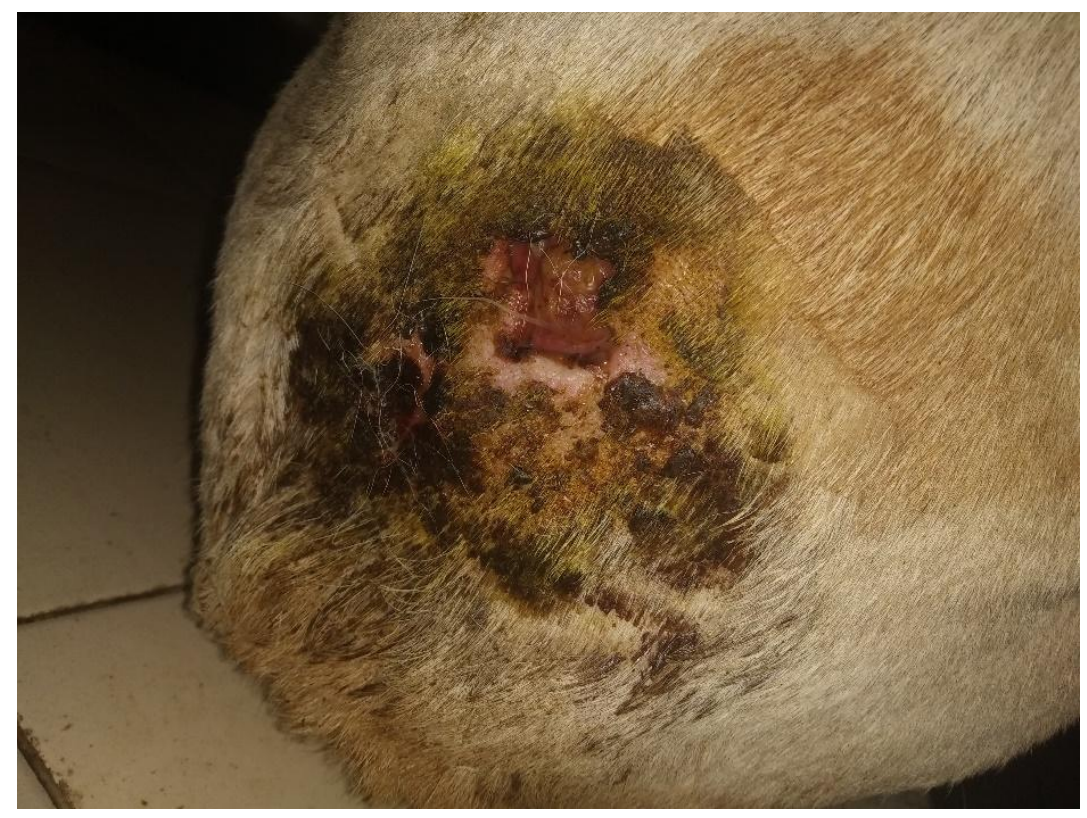

Recovery 15 days after treatment with Anbioflam

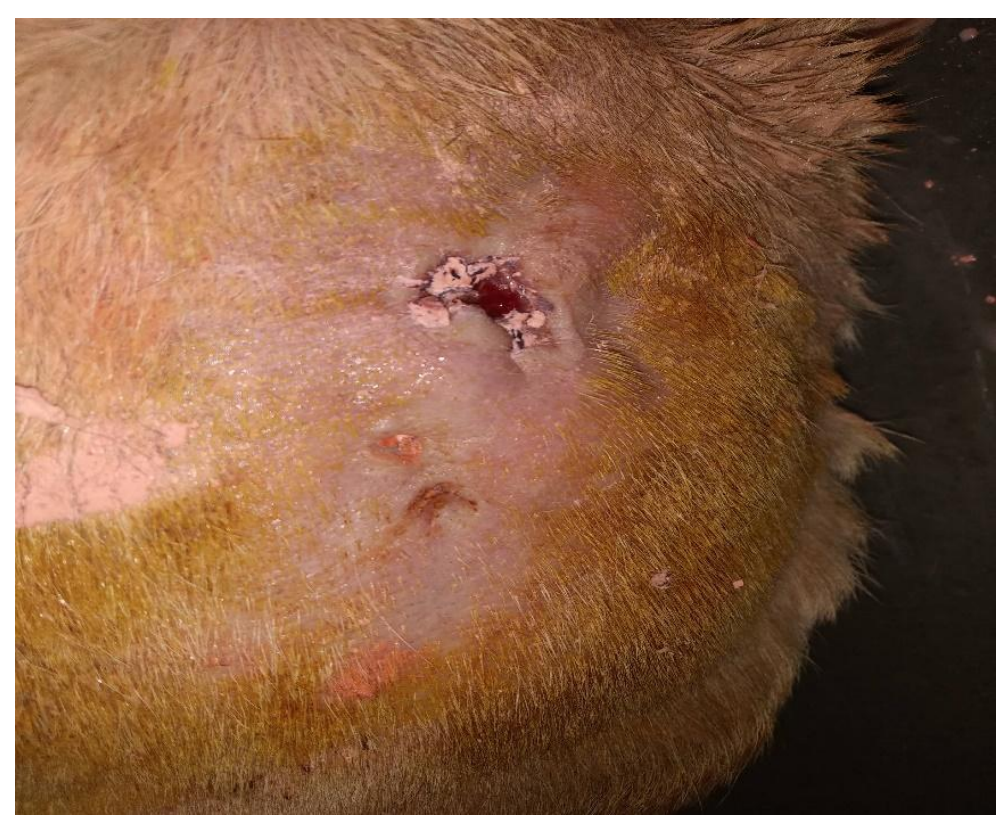


Case No.19 Dog having septic wound on testicle before treatment with Anbioflam Syrup

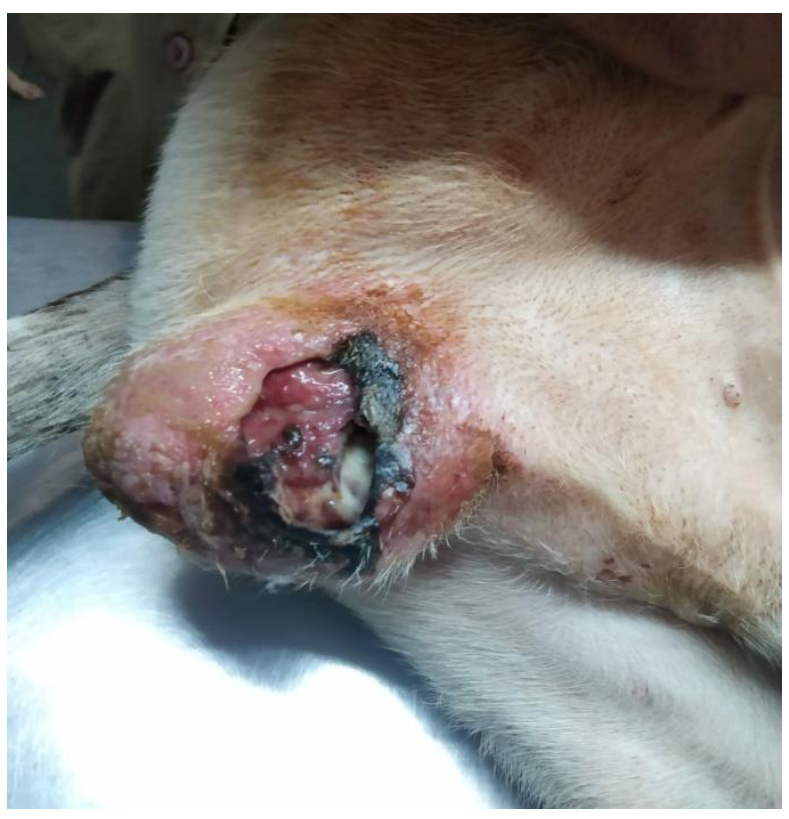

Recovery after 15 days treatment with Anbioflam Syrup

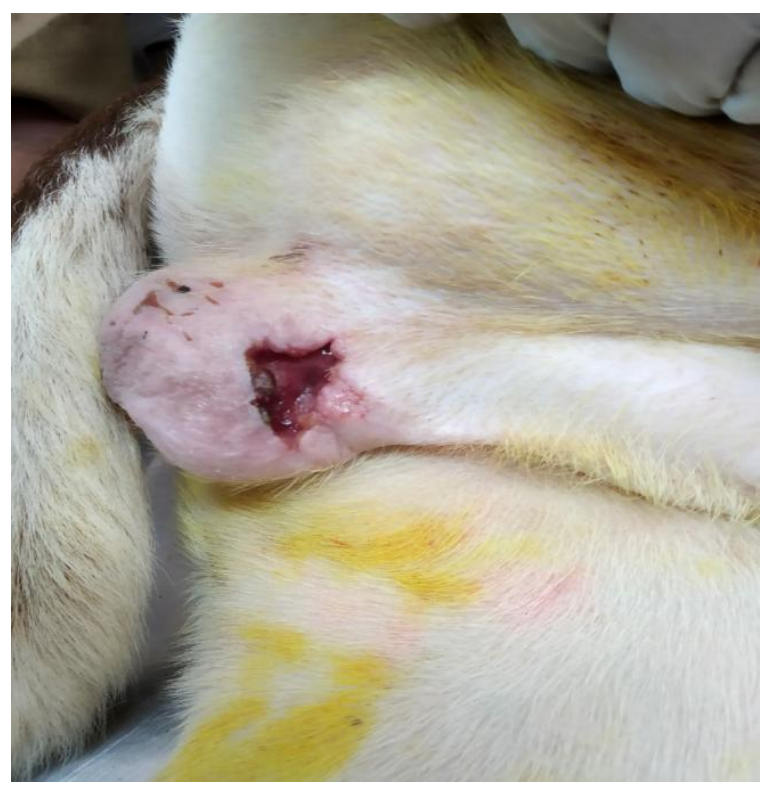


Case No.20 Case of dog having wound at the base of ear before treatment with Anbioflam Syrup

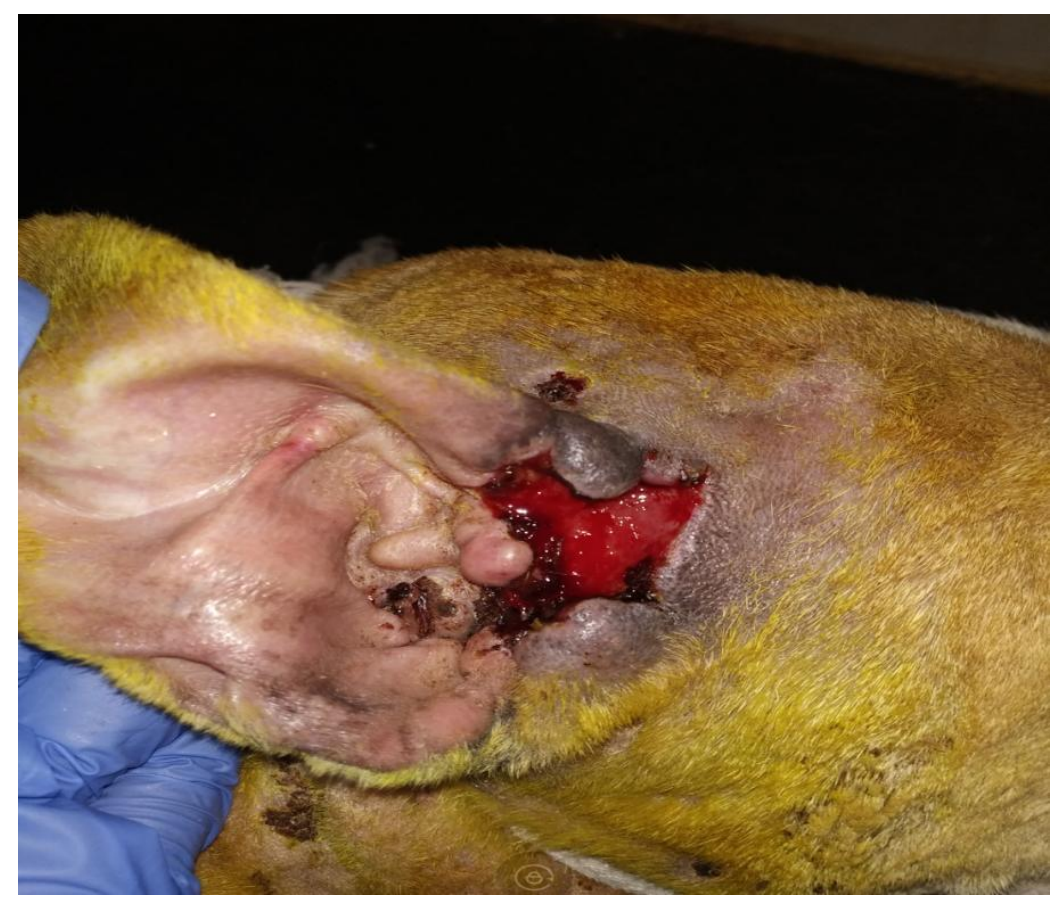

Recovery 15 days after treatment with Anbioflam

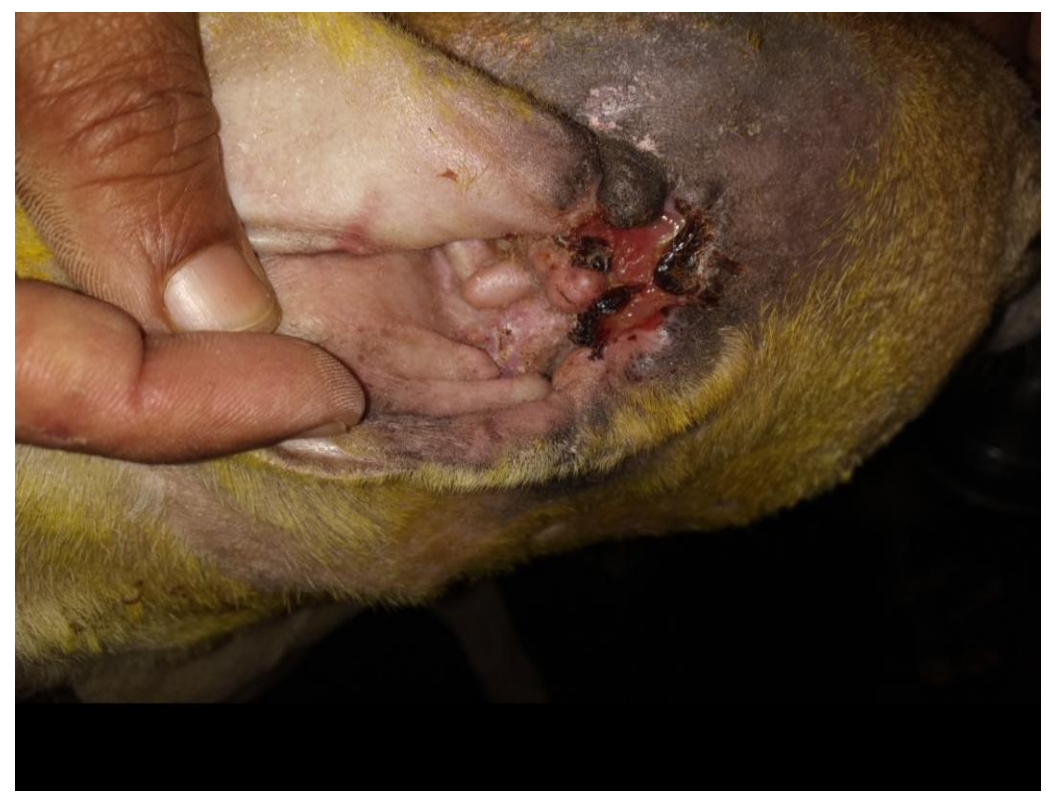

Anbioflam Syrup contains the turmeric as antimicrobial (Ammon and Wahl, 1991; Madhyasta and Bhat, 1985; Dahl et al., 1989).
Negi et al., (1999) reported the antibacterial activity of Curcuma longa by pour plate method against Bacillus cereus, Bacillus 
coagulans, Bacillus subtilis, Staphylococcus aureus, Escherichia coli, and Pseudomonas aeruginosa. Sholl et al., (2014) studied the Curcuma longa (Zingiberaceae family) and its polyphenolic compound curcumin have been subjected to a variety of antimicrobial investigations due to extensive traditional uses and low side effects. They also reported the antimicrobial activities for curcumin and rhizome extract of $C$. longa against different bacteria, viruses, fungi, and parasites.

In antibiotic sensitivity test, most of the isolates showed the sensitivity to Ceftriaxone, followed by Ciprofloxacin and Streptomycin. Thus, maximum effective antibiotic for treatment in most of cases found to be Ceftriaxone, followed by Enrofloxacin, Amoxyclave and Amikacin. Thus the antibiotics of choice for treatment were Ceftriaxone, Enrofloxacin, Amoxyclave and Amikacin.

\section{Recovery}

Syrup Anbioflam helped best in reduction of various clinical signs of inflammation like redness, abnormal heat, exudation, swelling, pain and vascular changes in the inflamed tissues in various surgical cases of dogs. Cedrus deodara and Curcuma longa present in the Anbioflam Syrup have resulted in the recovery of various clinical signs in the present study. Negi et al., (1999), Shinde et al., (1999), Sholl et al., (2014) and Vijayastelter (2011) reported similar effects of Cedrus deodara and Curcuma longa in experimental rats.

\section{Palatability}

The palatability on the basis of acceptability of Syrup Anbioflam by the dogs was evaluated and it was observed that it well accepted by the dogs.

\section{References}

Ammon, H. P. T., Wahl, M. A. Pharmacology of Curcuma longa. Planta Med. 1991, 57, 1-7.

Dahl, T. A., McGowan, W. M., Shand, M. A., Srinivasan, V. A. Phytokilling of bacteria by the natural dye curcumin. Arch. Microbiol. 1989, 151, 183-185.

Kirtikar, K.R., Basu, B.D., Blatter, E., Caius, J.F., Mhaskar, K.S. (1933). Indian Medicinal Plants. Lalit Mohan Basu, Allahabad, India, pp. 2390-2392.

Madhyastha, M. S., Bhat, R. V. Evaluation of substrate potentiality and inhibitory effects to identify high risk spices for aflatoxin contamination. J. Food Sci. 1985, 50, 376378.

Naganawa. Negi, P. S., Jayaprakasha, G. K. Rao, L. J. M.andand Sakariah K. K. (1999). Antibacterial Activity of Turmeric Oil: A By product from Curcumin Manufacture", J.Agric.Food Chem. 47, 4297-4300.

Shinde, U.A., Phadke, A.S, Nair, A.M, Mungantiwar, A.A, Dikshit, V.J, Saraf, M.N. (1999) "Studies on the antiinflammatory and analgesic activity of Cedrus deodara (Roxb.) Loud. wood oil", Journal of Ethnopharmacology 65, 21-27.

Shinde, U.A., Phadke, A.S, Nair, A.M, Mungantiwar, A.A, Dikshit, V.J, Saraf, M.N. (1999) "Preliminary studies on the immunomodulatory activity of Cedrusdeodara wood oil", Fitoterapia 70, 333 -339.

Soheil Z. M., Habsah A. K., Pouya H,, Hassan T., Sazaly A., and Keivan Z, (2014) "A Review on Antibacterial, Antiviral, and Antifungal Activity of Curcumin" Hindawi Publishing Corporation BioMed Research International Volume, Article ID 186864, 12 pages.

Vijayastelter B. L., Kottarapat J., Ramadasan, K. (2011). An evaluation of antioxidant, antiinflammatory, and antinociceptive activities of essential oil from Curcuma longa L. Indian Journal of Pharmacology, 43(5): 526-531. 


\section{How to cite this article:}

Yadav, G. U., D. U. Lokhande and Gandge, R. S. 2020. Efficacy of Anbioflam Syrup in Wounds and Dermatological Disorders in Dogs. Int.J.Curr.Microbiol.App.Sci. 9(06): 814-822. doi: https://doi.org/10.20546/ijcmas.2020.906.104 